\title{
Radikal human
}

\section{Adrian Ritter}

Freier Journalist

\author{
Für sein Engagement für die Opfer von Konflikten ist der italienische Chirurg Gino \\ Strada mit einem der "Alternativen Nobelpreise» des Jahres 2015 ausgezeichnet \\ worden. Die Ehre geht an einen radikalen Humanisten, der gegen Krieg und für das \\ Menschenrecht auf Gesundheit eintritt.
}

Gino Strada hat viel Leid gesehen und die Hoffnung doch nicht aufgegeben. Im Gegenteil: Die von ihm 1994 mitbegründete Nichtregierungsorganisation Emergency hat Millionen von Menschen geholfen und Tausende von Leben gerettet. Sie unterhält mehr als 60 Krankenhäuser und Erste-Hilfe-Stationen in Konfliktgebieten in aller Welt. Mehr als 6,5 Millionen Patienten wurden bis heute dort behandelt.

Nach der Ausbildung zum Chirurgen in Milano war Gino Strada in Spitälern in Italien, Südafrika und den USA tätig. Er unterbrach die lukrative Karriere 1989, um für das Internationale Komitee des Roten Kreuzes mehrere Jahre als Kriegschirurg zu arbeiten. Anschliessend begann er mit Emergency seine eigenen Vorstellungen von Hilfe in Konfliktgebieten umzusetzen.

Gino Strada gleicht in seinen Überzeugungen eher einem jungen, idealistischen Pazifisten denn dem 67-jährigen, welterfahrenen Macher, der er ist. Genau diese Mischung aus dezidierter politischer Position und praktischer Arbeit im Feld hat die Stiftung Right Livelihood Award bewogen, ihn mit einem der «Alternativen Nobelpreise» des Jahres 2015 auszuzeichnen «für die Schaffung hervorragender medizinischer und chirurgischer Nothilfe für die Opfer von Konflikt und Ungerechtigkeit und für seinen furchtlosen Einsatz gegen die Ursachen von Krieg».

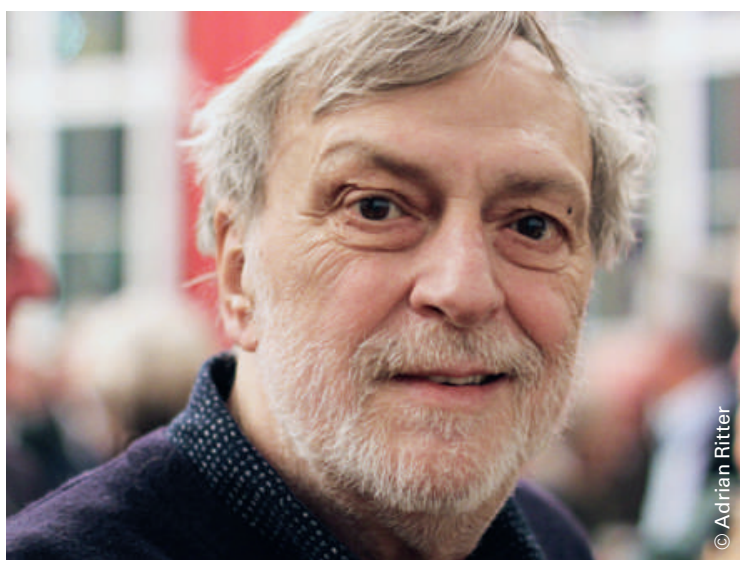

Der Preisträger Gino Strada - seine Organisation Emergency unterhält weltweit in Konfliktgebieten mehr als 60 Krankenhäuser und Erste-Hilfe-Stationen.
In einer Rede an der Universität Zürich erläuterte Gino Strada im Dezember seine Grundideen. So ist er überzeugt: «Es gibt keine Rechtfertigung für Krieg. Kriege kann man auch mit Konventionen nicht humaner machen.» Das zeigt sich Strada unter anderem darin, dass sich der Anteil der zivilen Opfer in Kriegen vom Ersten Weltkrieg bis heute von 15 Prozent auf über 90 Prozent erhöht hat. "Krieg sollte abgeschafft werden - diese Idee gilt es neu zu denken", sagte Strada. So sprach sich Emergency gegen die Beteiligung Italiens an den Einsätzen in Afghanistan und im Irak aus und spielte eine führende Rolle in der Kampagne gegen die Verbreitung von Landminen. Dies mündete 1997 in Italien in ein Verbot der Produktion und Nutzung dieser Waffen.

\section{Exzellenz für Afrika}

Radikaler Humanist ist Gino Strada auch, indem er das Menschenrecht auf Gesundheit ernst nimmt und umsetzt. "Jeder Mensch auf der Welt hat das Recht auf eine qualitativ hochstehende, kostenlose medizinische Behandlung», so sein Credo. Entsprechend bietet Emergency von Afghanistan bis Sierra Leone medizinische Versorgung auf höchstem Niveau: Chirurgische Kliniken, pädiatrische Einrichtungen und Rehabilitationszentren sind zum Nulltarif zugänglich und entsprechen dem neuesten Stand der Technik und Ausbildung. Es könne keine spezifische Qualität je nach Kontinent geben. «Ein Spital in Afrika ist gut genug, wenn es auch für die Behandlung meiner Freunde zu Hause gut genug ist", so Strada.

In Sudan hat Emergency ein erstklassiges Zentrum für Herzchirurgie eröffnet. Elf weitere Centres of Excellence in Afrika sollen folgen. Strada rechnet mit Kosten in der Höhe von 250 Millionen Euro für den Bau und die ersten Betriebsjahre. Kein Pappenstil für eine Nichtregierungsorganisation, die sich vor allem über Kleinspenden und über Beiträge von Gesundheitsministerien finanziert. Aber ein Ding der Unmöglichkeit? Davon will Gino Strada nichts hören: «250 Millionen Euro, so viel kostet ein Tag Krieg in Afghanistan. Das Geld ist also vorhanden. Die Frage ist, wofür man es ausgibt.» 